\title{
Autosomal Dominant Osteopetrosis Type II
}

\author{
Hsuan-Ming Lin ${ }^{1,2}$, Chiz-Tzung Chang ${ }^{1,2}$ and Chiu-Ching Huang ${ }^{1,2}$
}

Key words: osteopetrosis, osteoclast chloride channel gene

(Intern Med 50: 2695-2696, 2011)

(DOI: 10.2169/internalmedicine.50.6364)

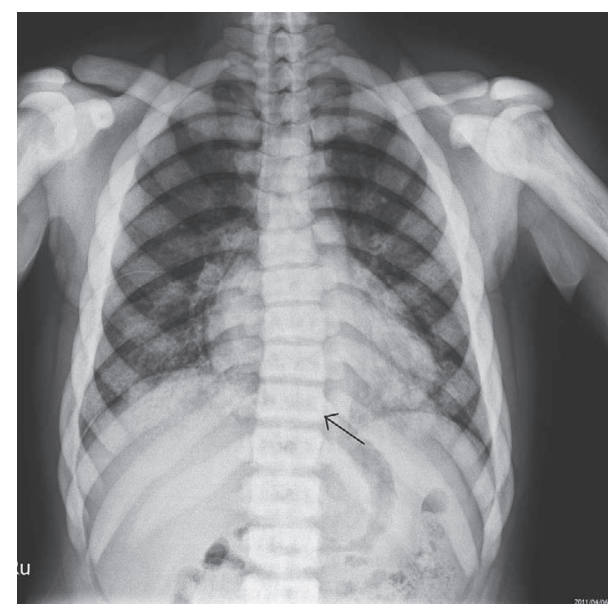

Picture 1.

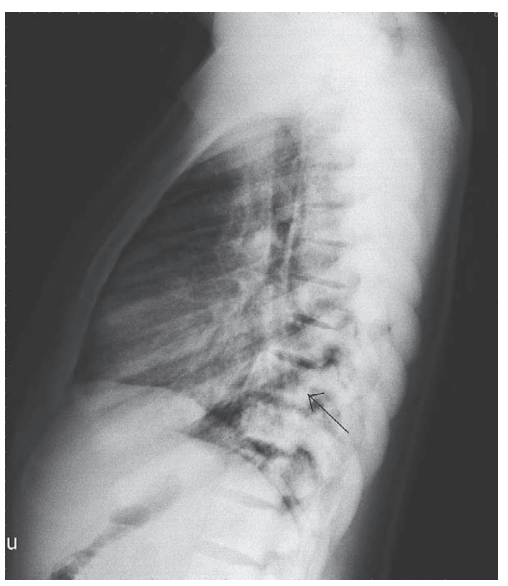

Picture 2.

A 24-year-old previous healthy man, with no contributory family history, came to our clinic due to dyspnea and poor appetite for two weeks. In our clinics, we took a chest Xray and a kidney, ureter and bladder (KUB) X-ray. Chest Xray demonstrated a generalized increase of bone density (Picture 1) and vertebrae end-plate sclerotic thickening-the

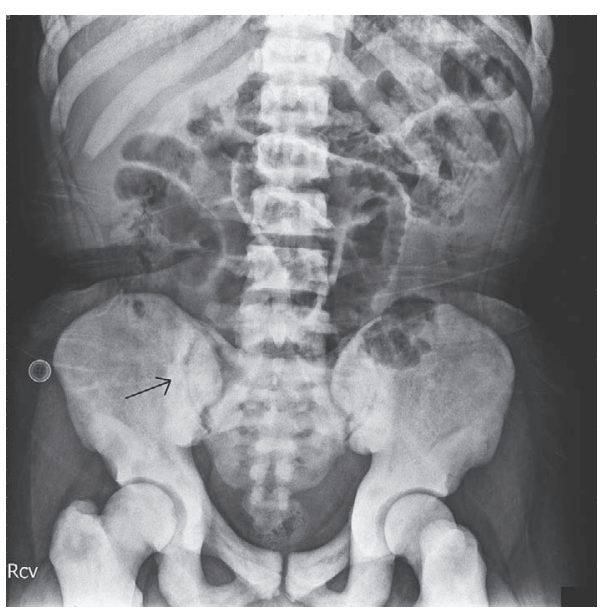

Picture 3.

so-called "sandwich vertebra" appearance (Picture 2 arrow). KUB showed a typical "bone within a bone" lesion in his pelvis (Picture 3 arrow). Renal echogram revealed bilateral small kidneys without calcification or stones. Autosomal dominant osteopetrosis type II (ADOII) was diagnosed.

ADOII is a disorder with late-childhood or adult onset. Osteoclast chloride channel gene mutation (CLCN7) is responsible for the clinical manifestations. Generalized osteosclerosis developed secondary to osteoclast dysfunction. Osteosclerosis can affect the shape and structure of the bone. Some patients develop cranial nerve dysfunction or visual deficits due to osteosclerosis of skull bone and some develop bone marrow failure as a result of bone marrow cavity involvement $(1,2)$.

The authors state that they have no Conflict of Interest (COI).

\section{References}

1. Tolar J, Teitelbaum SL, Orchard PJ. Osteopetrosis. N Engl J Med 351: 2839-2849, 2004.

2. Waguespack SG, Koller DL, White KE, et al. Chloride channel 7

${ }^{1}$ Divison of Nephrology, China Medical University Hospital, Taiwan and ${ }^{2}$ College of Medicine, China Medical University, Taiwan Received for publication August 9, 2011; Accepted for publication August 18, 2011 Correspondence to Dr. Chiz-Tzung Chang, d19863@mail.cmuh.org.tw 
Intern Med 50: 2695-2696, 2011 DOI: 10.2169/internalmedicine.50.6364

(ClCN7) gene mutations and autosomal dominant osteopetrosis, $\quad$ type II. J Bone Miner Res 18: 1513-1518, 2003.

(C) 2011 The Japanese Society of Internal Medicine http://www.naika.or.jp/imindex.html 